\title{
Placenta percreta following first trimester miscarriage
}

\author{
P.K. Brahma ${ }^{\text {a }}$, R. Lieberman ${ }^{\text {b }}$, C. Przybycin ${ }^{\text {b }}$, J.R. Liu ${ }^{a, *}$ \\ a Department of Obstetrics and Gynecology, University of Michigan, Ann Arbor, MI, USA \\ ${ }^{b}$ Department of Pathology, University of Michigan, Ann Arbor, MI, USA
}

Received 6 April 2007; received in revised form 25 April 2007; accepted 25 April 2007

\section{KEYWORDS \\ Placenta percreta; \\ First trimester miscarriage}

The incidence of placenta accreta ranges from 1:2500 to 1:7000 births $[1,2]$. The incidence of placenta percreta has steadily risen over the past several decades [3]. Although improvements in documentation have occurred, an increase in patients with relevant risk factors parallels the increase in incidence. Risk factors for the development of abnormal placentation include: previous cesarean deliveries, placenta previa, maternal age greater than 35 years, high gravidity, multiparity, and previous curettage $[1,2]$.

A 34-year-old woman (gravida 6, para 1) presented for evaluation with the diagnosis of a large vascular uterine mass, 4 months after having a dilation and curettage (D\&C) for completion of a first trimester miscarriage. At the time of her $D \& C$, she was at 8 weeks of gestation, and the quantitative betahuman chorionic gonadotropin ( $\beta$ hCG) was $169,585 \mathrm{mlU} / \mathrm{mL}$. The patient's obstetric history was significant for a previous low transverse cesarean delivery performed at 36 weeks secondary to known vasa previa and bilobed placenta. Additionally, she had undergone five prior D\&Cs, for first trimester elective and spontaneous abortions.

Pathologic evaluation following D\&C showed products of conception; however, the patient had persistent vaginal bleeding. Serial transvaginal ultrasounds revealed a complex mass seen in the anterior lower uterine segment. Magnetic resonance imaging (MRI) revealed a large pelvic mass with areas of nonenhancement consistent with possible necrosis (Fig. 1). The mass abutted the right pelvic wall, bladder, and rectum, though it did not clearly invade these structures. A computerized tomography (CT) scan showed no adenopathy or extrauterine masses.

Differential diagnosis at the time included placental site trophoblastic tumor, persistent placental tissue, or other uterine tumors including a degenerating fibroid. The patient was counseled to undergo an examination under anesthesia, and ultrasound-guided D\&C. The $\beta$ hCG at the time was $3 \mathrm{mlU} / \mathrm{mL}$,

\footnotetext{
* Corresponding author. 4219 CCGC, 1500 East Medical Center Drive, Ann Arbor, MI 48109, USA. Tel./fax: +1 7349363024.

E-mail address: rliu@umich.edu (J.R. Liu).
}

and serum human placental lactogen was $<0.10 \mu \mathrm{g} / \mathrm{mL}$. The patient desired fertility preservation, but given the possibility of myometrial invasion, the patient gave informed consent for hysterectomy.

A D\&C was attempted, however, sonographic guidance revealed that the uterine mass was not clearly contiguous with the endometrial cavity. Exploratory laparotomy was performed which revealed an enlarged, necrotic, hemorrhagic mass measuring $4 \times 6 \mathrm{~cm}$ that protruded from the anterior lower uterine segment, and was densely adhered to the bladder. Upon attempted biopsy of the mass, a rapid loss of $500 \mathrm{~cm}^{3}$ of blood occurred, resulting in a total abdominal hysterectomy. The preliminary intraoperative pathology report was consistent with necrosis and possible placental site trophoblastic tumor. Total operative blood loss was $1000 \mathrm{~cm}^{3}$, and the patient's postoperative course was unremarkable.

Final pathology revealed extensively necrotic placental tissue extending from the anterior endometrial cavity, through the myometrium to the uterine serosa (Fig. 2). The majority of the placental tissue was extrauterine, consistent with necrotic placenta percreta. In this case, the symptoms of persistent vaginal bleeding and the development of a large vascular uterine mass 4 months following a first trimester D\&C were suggestive of malignancy. This patient was at high risk of abnormal placentation, given her history of multiple uterine curettages and one prior cesarean delivery.

Placenta percreta can lead to disastrous complications, including uterine rupture, abolished future fertility, and even

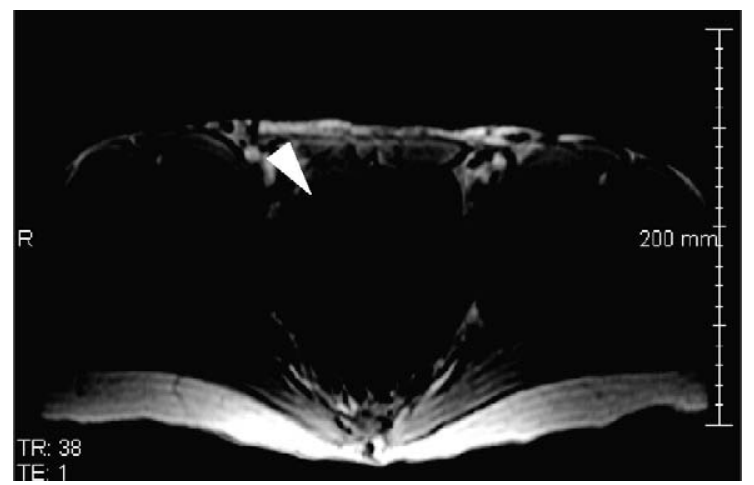

Figure 1 Gadolinium-enhanced T1-weighted MRI shows a large anterior-uterine mass (arrow) adjacent to the right pelvic sidewall, bladder, and rectum. 

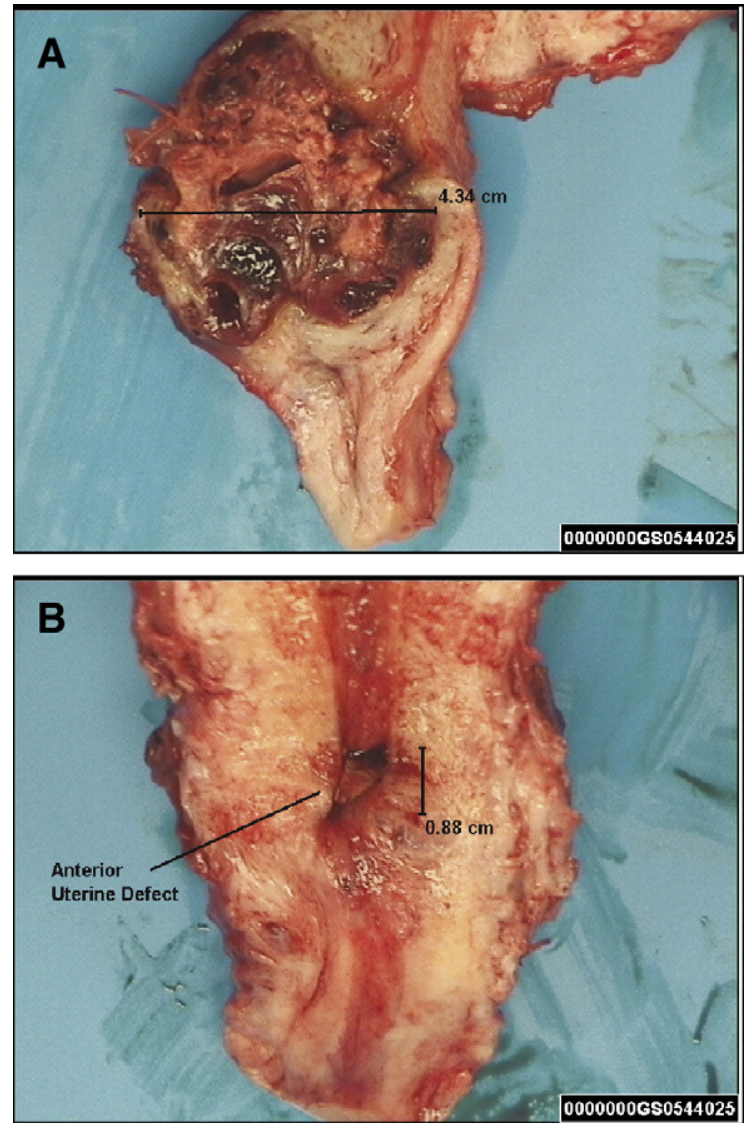

Figure 2 (A) Cross-section of uterus, revealing large vessels and necrosis. (B) Bivalved uterine section, revealing anterior uterine defect. death. The detection of placenta percreta in the first trimester is very rare, and raises clinical questions regarding the use of detailed imaging in high risk patients with persistent bleeding. A search of the literature revealed only a few other cases of placenta percreta at this early gestational age. The correlation between placenta percreta and patients with previous cesarean delivery and multiple uterine curettages is significant. When evaluating patients with persistent first trimester vaginal bleeding who have risk factors for abnormal placentation, high clinical suspicion should lead to prompt imaging studies to avoid the potential catastrophic outcomes associated with placenta percreta.

\section{References}

[1] Weckstein LN, Masserman JS, Garite TJ. Placenta accreta: a problem of increasing clinical significance. Obstet Gynecol 1987;69:480-2.

[2] Miller DA, Chollet JA, Godwin TM. Clinical risk factors for placenta previa-placenta accreta. Am J Obstet Gynecol 1997; 177:210-4.

[3] deRoux SJ, Prendergast NC, Adsay NV. Spontaneous uterine rupture with fatal hemoperitoneum due to placenta accreta percreta: a case report and review of the literature. Int J Gynecol Pathol 1999;18:82-6. 